NOTICE: this is the author's version of a work that was accepted for publication by the American Society of Civil Engineers. The published version is available at http://cedb.asce.org/cgi/WWWdisplay.cgi?261181 


\title{
Implementation of Optimized Soil Improvement Techniques for a Giga Project
}

\author{
Babak Hamidi ${ }^{1}$, Serge Varaksin ${ }^{2}$ and Hamid Nikraz ${ }^{3}$ \\ ${ }^{1} \mathrm{PhD}$ Candidate, Curtin University of Technology, 5/531Hay Street, Subiaco 6008 WA, Australia; \\ babak.hamidi@postgrad.curtin.edu.au \\ ${ }^{2}$ Deputy General Manager, Menard; Chairman, ISSMFE TC17, 2 rue Gutenberg, BP 28, 91620 Nozay \\ France; serge.varaksin@menard-mail.com \\ ${ }^{3}$ Professor and Head of Civil Engineering Department, Curtin University of Technology, GPO Box \\ U1987 Perth WA, Australia; h.nikraz@curtin.edu.au
}

\begin{abstract}
One of the world's largest ground improvement projects that has ever been carried out in one phase by a single specialist ground improvement contractor is the 2,600,000 $\mathrm{m}^{2}$ King Abdulla University of Science and Technology in Jeddah. What has made this project perhaps one of the most unique ground improvement accomplishments ever is not only its size but also the ability to interpret the ground conditions based on limited geotechnical investigation and the ground's behavior during the treatment, the know-how to adapt the solution to late architectural and structural changes, and the capacity to execute the works by an optimized combination of Dynamic Compaction, Dynamic Replacement, High Energy Dynamic Replacement and Dynamic Surcharging.
\end{abstract}

\section{INTRODUCTION}

The 5.6 million $\mathrm{m}^{2}$ King Abdulla University of Science and Technology (KAUST) is located in Rabigh on the Red Sea coast and near the city of Jeddah in Saudi Arabia. KAUST, originally anticipated to have buildings with at most two to three stories, includes the university campus and academic administration core, a desalination plant, wind turbines, residential neighborhoods, a research park, a commercial center, a waste water treatment plant and a beach club.

The concept of the project was developed in 2006. According to the schedule, master planning, architectural and structural design and construction had to be completed in less than three years and handover date was set at September 2009.

The preliminary geotechnical investigation that was carried out in a relatively wide grid indicated that the ground was very heterogeneous and composed of a 
combination of loose or soft soils with rapid variations within short distances. This investigation and further testing during the works revealed that more than 2.6 million $\mathrm{m}^{2}$ of the construction area was to be built on soil consisting of up to $9 \mathrm{~m}$ of loose silty sand or soft sandy silt (locally called sabkah). A generalized profile of the ground and a summary of the test results for each soil layer are respectively shown in Fig. 1 and Table 1.

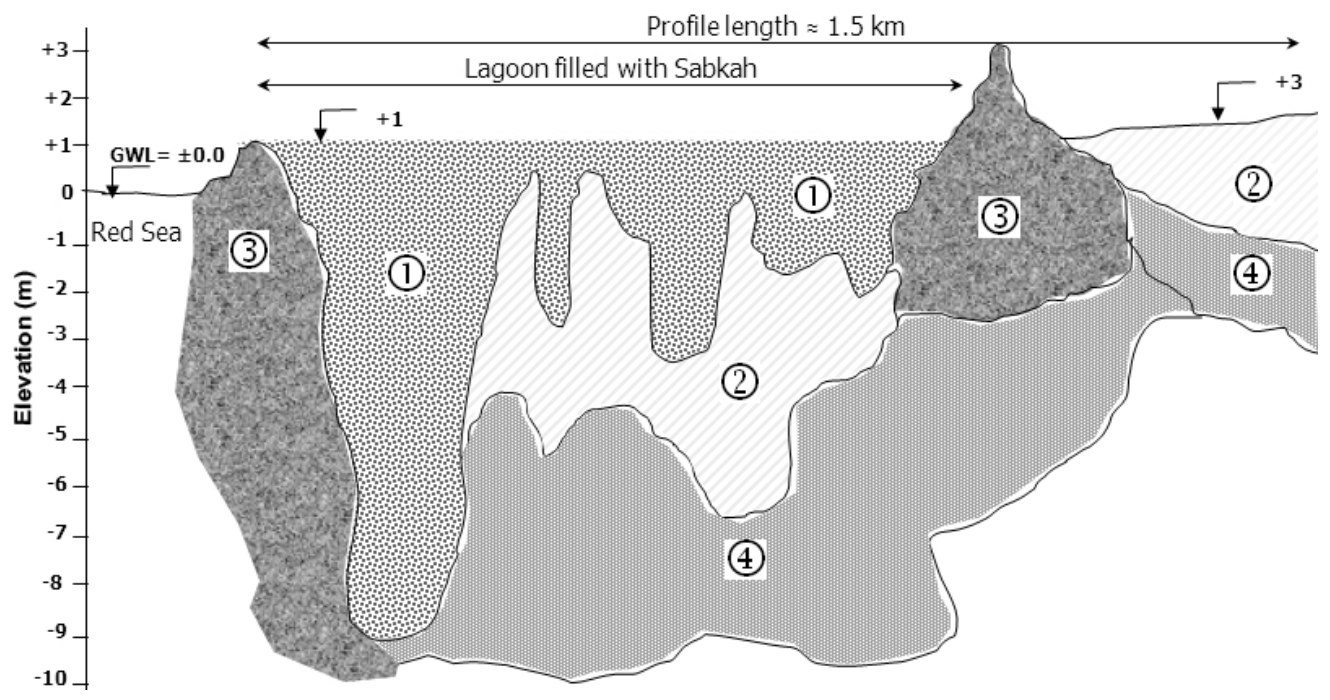

Fig. 1. Ground profile in KAUST

As groundwater table was less than $1 \mathrm{~m}$ below in-situ ground level it was decided that the final ground level (FGL) had to about $3 \mathrm{~m}$ above original levels to be safely above high tide levels.

It was evident that only a well worked out schedule that incorporated design and construction could meet the project's deadline. However, the problematic soil posed a serious threat to this program as it was not possible to design the foundations without the finalization of the buildings' locations and architectural drawings. Thus a delay in construction seemed inevitable.

Table 1. Ground conditions in KAUST

\begin{tabular}{|l|c|c|c|c|c|c|c|}
\hline \multirow{2}{*}{ Layer \& USC } & \multirow{2}{*}{$\begin{array}{c}\text { Water } \\
\text { Content }\end{array}$} & \multirow{2}{*}{$\begin{array}{c}\text { Fines } \\
\text { Content }\end{array}$} & $\mathbf{N}_{\text {SPT }}$ & \multicolumn{2}{|c|}{ CPT } & \multicolumn{2}{|c|}{ PMT } \\
\cline { 5 - 8 } & & $\begin{array}{c}\mathbf{q}_{\mathbf{c}} \\
(\mathbf{M P a})\end{array}$ & $\mathbf{f}_{\mathbf{r}}(\boldsymbol{\%})$ & $\mathbf{P}_{\mathbf{L}}(\mathbf{k P a})$ & $\begin{array}{c}\mathbf{E}_{\mathbf{p}} \\
(\mathbf{M P a})\end{array}$ \\
\hline $\begin{array}{c}\text { 1- Sabkah } \\
\text { (SM+ML) }\end{array}$ & $35-48 \%$ & $28-56 \%$ & $0-2$ & $0-0.2$ & $1.2-4.0$ & $40-190$ & $0.4-1.7$ \\
\hline $\begin{array}{c}\text { 2- Silty Sand } \\
\text { (SM) }\end{array}$ & - & $15-28 \%$ & $3-9$ & $1.2-4.5$ & $0.5-1.2$ & $210-400$ & $1.8-3.5$ \\
\hline 3- Coral & $26-35 \%$ & - & $6-12$ & - & - & $510-720$ & $3.5-6.0$ \\
\hline 4- Sand (SM) & - & $12-37 \%$ & $3-18$ & $1.5-1.8$ & $0.5-1.8$ & $400-1200$ & $2.8-8.5$ \\
\hline
\end{tabular}




\section{DEVELOPMENT, EXECUTION AND TESTING OF THE FOUNDATION SOLUTION}

All possible foundation solutions were considered. Piling was immediately deemed as infeasible because without architectural and structural design it was not possible to define the pile locations. Thus, only ground improvement remained as a potential solution.

The design and construct (D\&C) ground improvement proposal that met the project manager's technical requirements, schedule and budget was based on the below design criteria:

- Footing location: Any place within the treatment area

○ Maximum footing load: $1,500 \mathrm{kN}$

- Allowable bearing capacity: $200 \mathrm{kPa}$

○ Maximum total settlement: $25 \mathrm{~mm}$

- Maximum differential settlement between two adjacent footings: 1/500

- Liquefaction mitigation for an earthquake with $\mathrm{PGA}=0.07 \mathrm{~g}$

$\circ$ Level: $0.8 \mathrm{~m}$ below final ground level, but in any case at least $2 \mathrm{~m}$ above sabkah level

The construction method was composed of a combination of Dynamic Compaction (DC) (Menard, 1972, 1974; Chu et al, 2009), Dynamic Replacement (DR) (Menard and Broise, 1975), and High Energy Dynamic Replacement (HDR). Changes to the height (and consequently footing loads) of some buildings later introduced the need to also utilize Dynamic Surcharging (DS) (Al Hamoud, 2005).

The working platform was constructed by dumping and leveling 1 to $1.5 \mathrm{~m}$ of granular fill. Roller compaction was not necessary as the platform material was to be compacted in the process of soil improvement works. This of course, was advantageous because not only was the cost of watering, removal of oversize material, mixing and roller compaction eliminated, but more importantly since precious construction time was saved.

In DC, granular soil is compacted using impact energy that is delivered by dropping a heavy weight or pounder from a significant height (Hamidi et al, 2009). In KAUST this technique was used to compact soils with fines content up to about 30 to $35 \%$ using pounders weighing up to 21 tons.

In DR, a heavy pounder is dropped to create a cavity in soft soils which is then backfilled with granular material that dynamically driven to the bottom of the soft soil layer or down to a depth of about 5 to $6 \mathrm{~m}$. DR technique was used in areas where the maximum depth of sabkah was $5 \mathrm{~m}$. HDR was used when the sabkah layer's depth was more than $5 \mathrm{~m}$. In such a case, a $3 \mathrm{~m}$ surcharge, in addition to the engineered fill required for reaching FGL, was placed over the area for 3 weeks. 
After the completion of ground treatment in specific areas, it became known that the revised master plan incorporated 20 six-story. Consequently and as shown in Fig. 2, DS was also used to consolidate the deep sabkah layers. In this technique the combination of preloading and vibration is used to re-introduce pore pressure in the soil-water system and consequently to accelerate settlement rates (Menard and Broise, 1975). Hence, in addition to the engineered fill required for reaching FGL a 3 $\mathrm{m}$ high surcharge was place and DC was performed on top of it.

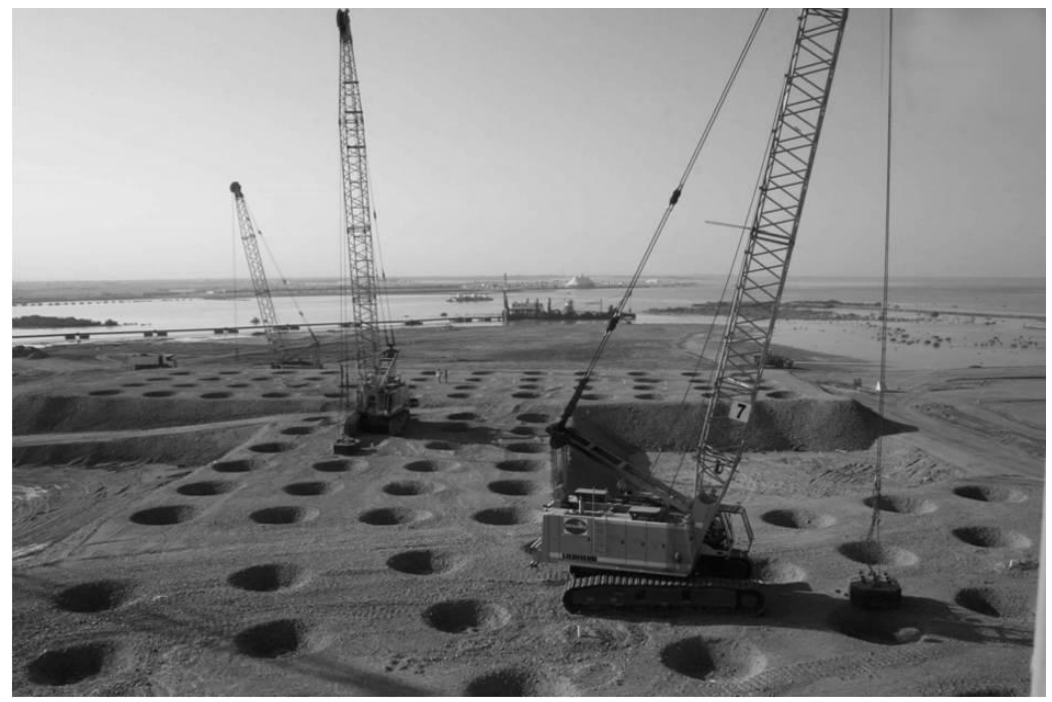

Fig. 2. Dynamic Surcharging in KAUST

Differences in ground behavior due to pounder impact enabled the site supervisors to assess the rapidly varying ground conditions and to apply the appropriate ground improvement technique as needed. It was observed that while the first DC pounder impact penetrated the ground by about $0.25 \mathrm{~m}$, the DR pounder penetration was substantially more and in the range of about $1 \mathrm{~m}$. Also, performing DC frequently resulted in the seepage of groundwater to the surface, but this phenomenon was rarely encountered in the DR areas. Ground rest periods in between DC phases were 1 to 3 days. However, this period was considerably longer and from 7 to 21 days when DR was utilized. Furthermore, ground heave due to pounding was not observed in DC areas but was quite evident in DR zones.

The allocated time frame for mobilization, execution and testing of ground improvement works was set at 10 months. Ground improvement was carried out basically over a period of 8 months using a total of 13 DC/DR/HDR-DS rigs working two shifts per day. To the knowledge of the authors, this is the world record for the number of DC rigs working at the same time on a single project. A review of the treatment rates shows that at its peak, about $600,000 \mathrm{~m}^{2}$ of ground was treated in one month.

In all, a total of 180 PMT tests were carried out to confirm that the bearing and settlements had been achieved. A number of CPT were also performed for 
verification of liquefaction mitigation.

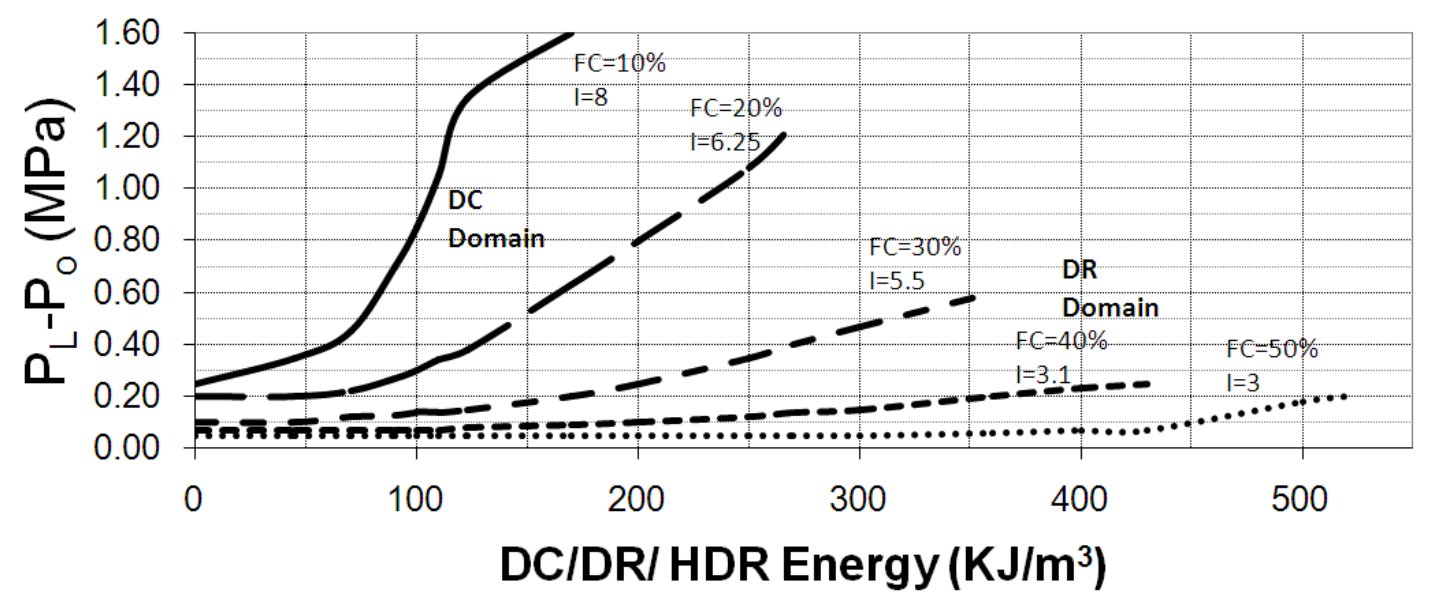

Fig. 3. The relationship between net limit pressure and improvement energy

Due to the wide range of ground conditions, including soil classification, strength, and thickness of layers, test results showed a wide range of results. Although the results clearly demonstrated that design criteria had been satisfied, it is interesting to note that it is possible to classify the test results according to the amount of dynamic energy applied to the ground and the amount of improvement. Fig. 3 shows the relation between the net pressuremeter limit pressure $\left(\mathrm{P}_{\mathrm{L}}-\mathrm{P}_{\mathrm{o}}\right)$ and the energy per volume of improved soil. As expected, it can be observed that the improvement factor (I) or the post to pre soil improvement net limit pressure ratio (only the in situ soil without the DR columns) is higher and more efficient when the soil is more granular and contains lesser fines. Furthermore, it can be noted that the DR columns play a vital role in providing the required ground properties in the sabkah soils, and their exclusion will result in failure of satisfying the design criteria.

\section{LESSONS LEARNED}

In this paper it has been demonstrated that classical solutions are not able to meet the requirements of special projects in which the site is unusually large, preliminary field tests are most probably insufficient, design and construction period is relatively short, and construction must commence parallel to the preparation of the architectural and structural drawings. However it is possible to construct such a project successfully if:

- Design and construction phases are merged smartly and efficiently.

- Design criteria are specified based on the actual project requirements rather than copy and pasting specifications from past projects.

- A combination of ground improvement techniques are used for treating different ground conditions rather than forcefully trying to implement one technique to a variety of different conditions. Furthermore, it may be more efficient to provide different amounts of treatment for each technique. 
- The limits of each technique are well understood.

- Possible production rates are well understood and sufficient amounts of plant and equipment are mobilized.

- Site observations are given value and changes in actual ground conditions are taken into account during the process of the works.

\section{CONCLUSION}

In KAUST, the combination of DC, DR and HDR was able to provide safe foundations at any undefined location. Last moment changes in the master plan and the introduction of heavier loads were taken into account by additionally implementing DS.

The heterogeneity of the site and rapid variations of ground conditions would have normally required excessive amounts of field testing which would have inevitably forced considerable delays in the completion date of the project. Alternatively, field observations of the ground behavior during the works proved to be the ultimate method for defining an optimized treatment area for each technique.

Professional project management skills and planning allowed the allocation of sufficient numbers of equipment and rigs, and ground improvement production rates as high as $600,000 \mathrm{~m}^{2} /$ month permitted the works to be completed in due time and in accordance to the construction schedule.

\section{ACKNOWLEDGMENT}

The authors would like to express their gratitude and appreciation to Menard for providing the project information.

\section{REFERENCES}

Al Hamoud, A. S. (2005) An Innovative Soil Improvement Under Raft Foundation by a Combination of Dynamic Surcharging and Dynamic Replacement. Association of Engineering Geologists Conference, Las Vegas, 19-24 September 2005.

Chu, J., Varaksin, S., Klotz, U. \& Menge, P. (2009) State of the Art Report: Construction Processes. 17th International Conference on Soil Mechanics \& Geotechnical Engineering: TC17 meeting ground improvement. Alexandria, Egypt, 130.

Hamidi, B., Nikraz, H. \& Varaksin, S. (2009) A Review on Impact Oriented Ground Improvement Techniques. Australian Geomechanics Journal, 44, 17-24.

Menard, L (1972). "La Consolidation Dynamique des Remblais Recents et Sols Compressibles", Travaux, (November): 56-60

Menard, L (1974). "La Consolidation Dynamique des Sols de Fondations." Revue des Sols et Fondations : 320

Menard, L and Broise, Y (1975). "Theoretical and Practical Aspects of Dynamic Compaction." Geotechnique, Vol. 25 (3): 3-18 